\title{
Behavioral factors contributing to the transmission of HIV and AIDS amongst young women of Mbabane in Swaziland
}

\author{
Johanes A Belle ${ }^{1}$, Nokuthula N Gamedze ${ }^{2}$
}

\begin{abstract}
1. University of the Free State, Faculty of Natural and Agricultural Sciences, Disaster Management Training and Education Centre for Africa, Tel: +27 51401 9702,Email: Belleja@ufs.ac.za,

2. Ministry of Health - Emergency Preparedness and Response Unit ; Swaziland, Tel: +268 24163626,

Email: thulagamedze@yahoo.co.uk
\end{abstract}

\begin{abstract}
:
Background: HIV and AIDS remains a pandemic that has greatly affected many regions and countries in the world. Africa is the hardest hit region by tthis disease while southern Africa appears to be the melting pot for HIV and AIDS. The HIV and AIDS pandemic remains the greatest sustainable human development and public health challenge for Swaziland. Swaziland is the world's worst affected country with the youth the most vulnerable group to HIV and AIDS due to many factors.

Objectives:'Methods: This study investigated the behavioral factors that contributed to the transmission of HIV and AIDS among female youth of Mbabane in Swaziland and to suggest measures that could encourage positive female youth behavior change in order to mitigate the spread and impacts of the pandemic. The study used a qualitative research approach in order to gain an in-depth experience of female youths in Mabane. Data were collected using a questionnaire, which were distributed to 210 randomly sampled females aged 16 to 24 years in Mbabane and who attended Mbabane Public Health Unit. The Behavior Change Communication (BCC) theoretical framework was usedin order to contextualize the study.

Results: Most respondents were female-single youth (64\%), almost half (45\%) had a high school education and most were unemployed $(57 \%)$ with little or no source of income. The majority $(88 \%)$ were sexually active and the main sources of HIV/AIDS transmission was through sex. For many (52\%) health facilities were their main source of HIV and AIDS information. The majority (97\%) were knowledgeable about HIV and AIDS, but casual sex, inconsistent condom usage and early sexual debut among others were still prevalent indicating resistance to behavior change.

Conclusion: The findings indicated that though the majority of the respondents had knowledge of HIV and AIDS, positive behavior change remained a challenge. Most respondents $(88 \%)$ had one sexual partner with $38 \%$ reporting condom use during their last sexual encounter. HIV/AIDS awareness was widespread. However, there were still characteristics of resistance to behavior change, because there was evidence of underestimation of HIV risk through engagement in behavior, which contributed to HIV infection and spread.Behavioral change measures using the BCC model is proposed

Keywords: BCC Model, behavior change, HIV, AIDS, youth, Swaziland.

DOI: https://dx.doi.org/10.4314/ahs.v19i3.2

Cite as: Belle JA, Gamedze NN. Behavioral factors contributing to the transmission of HIV and AIDS amongst young women of Mbabane in Swaziland. Afri Health Sci. 2019;19(3):2302-2311. bttps://dx.doi.org/10.4314/ahs.v19i3.2
\end{abstract}

\section{Introduction}

Swaziland is the epicenter of the global HIV and AIDS pandemic, with the world's highest prevalence rate estimated at $26 \%,{ }^{1,2-7}$. More than half of the population is under the age of 20 and nearly half of the youth are at an exceptionally high risk of HIV infection ${ }^{1,8-10}$. Over the years, Swaziland has made significant progress in the fight against HIV and AIDS, especially in prevention, treatment and mitigating the socio-economic impacts of the

\section{Corresponding author: \\ Johanes A Belle, \\ University of the Free State, \\ Faculty of Natural and Agricultural Sciences, \\ Disaster Management Training \\ and Education Centre for Africa, \\ Tel: +27 51401 9702, \\ Email: Belleja@ufs.ac.za}

pandemic, but a lot still remains to be done $e^{8-10,11-13}$. HIV and AIDS remains a global pandemic. By the end of the first decade in the $21^{\text {st }}$ century, approximated 33.3 million people were living with HIV compared to about 26.2 million in 1999, reflecting about 27 per cent increase $^{27}$. In 2010, young people aged 15-24 accounted for 42 per cent of new HIV infections and almost 80 per cent (4 million) of them live in sub-Saharan Africa. Young women and girls have special challenges which make them more vulnerable to HIV infection ${ }^{29}$.

Women account for more than half of all adults living with HIV and AIDS worldwide and beside natural factors, this sex disparity can be attributed to inequality in financial, physical and cultural power especially in sub-Sahara Africa. ${ }^{5,28}$

Globally, almost 6,000 youth aged between 15 and 24 years contract HIV daily and $85 \%$ of them live in developing countries ${ }^{4,11}$. Adolescence is an age of curiosity 
and exploration and the combination of this experimental period with other economic and socio-cultural factors make the youth particularly vulnerable to HIV infection ${ }^{30}$. Behaviours like unprotected sex, intravenous drug injection, presence of sexually transmitted infections (STIs), multiple sexual partners and substance abuse, early sexual initiation, lack of awareness in relation to HIV and AIDS, heterosexual transmission, poverty, school dropout were among the cited factors that fuel the transmission of HIV $^{6,30}$

Sub-Sahara Africa accounts for only 11 per cent of the global population, but has approximately 69 per cent of the world's PLHIV population portraying the region as the epicentre of HIV and AIDS ${ }^{20,28}$. The biggest HIV epidemic infections in sub-Saharan Africa in absolute numbers include South Africa (6.3 million), Nigeria (3.2 million people), Lesotho (360, 000), Botswana (320,000), and Swaziland $(200,000)^{27}$. However, the total number of new HIV infections in sub-Saharan Africa has dropped by more than 26 per cent, from 2.6 million in 1997 to 1.9 million in 2009. Another improvement trend is that the HIV incidence has fallen by more than 25 per cent between 2001 and 20095,6,27.

Literature indicates that the spread of the epidemic in Swaziland is fueled by behavioral, structural and biological drivers, which include multiple and concurrent sexual partners, low and inconsistent use of condoms, inter-generational sex, mobility and migration, commercial sex, early sexual debut, gender inequality and sexual violence, low levels of male circumcision, alcohol and drug abuse $e^{2-7,8-10,11-13,14}$. Income inequality, which is associated with many young Swazi girls engaging into transactional sex or sex for favors and in the process risking HIV infection, is high in Swaziland and also one of the main drivers of the epidemic ${ }^{7,15}$.

The first HIV infection in Swaziland was identified in 1986 and almost a decade later in 1999, HIV and AIDS was declared a national disaster by the Head of State, His Majesty King Mswati III. Since then, HIV and AIDS has become one of the Kingdom's leading public health concerns $^{8-11,16}$.

\section{Theory}

The study used the Behavior Change Communication (BCC) theoretical framework to address the problem and to discuss the research findings. The model has three broad sections that iclude the behavioral stages, then the enabling factors and lastly the communication channels as indicated in Figure 1. However, it should be noted that these levels are not sequential but interactive ${ }^{6}$.

The BCC framework provides developmental processes. Appropriate approaches and messages to promote positive behavior can be developed using the framework. Additionally, individual, community and societal behavior change as well as suitable behaviors can be promoted and sustained ${ }^{7}$. The BCC is therefore behaviorally focused and socio-culturally contextualized ${ }^{2}$ and has its background in behavior change theories that were developed over the past years ${ }^{2,6}$. It has become progressively clearer that improved education and knowledge do not automatically lead to positive behavioral change $e^{2}$ and therefore sustained behavior change is effective only when combined with changes in the broader socio-economic environment within which communities and individuals op$\operatorname{erate}^{2,17,18}$.

According to the BCC framework individuals and communities can reduce their risk level or change their behavior if they first comprehend the basic facts about HIV and AIDS and then assume key attitudes, learn a set of skills and are given access to appropriate services and products. The individuals must also ascertain their environment as supporting behavior change and safeguarding safe behaviors, as well as supportive of pursuing appropriate treatment for prevention and care $^{2}$. 


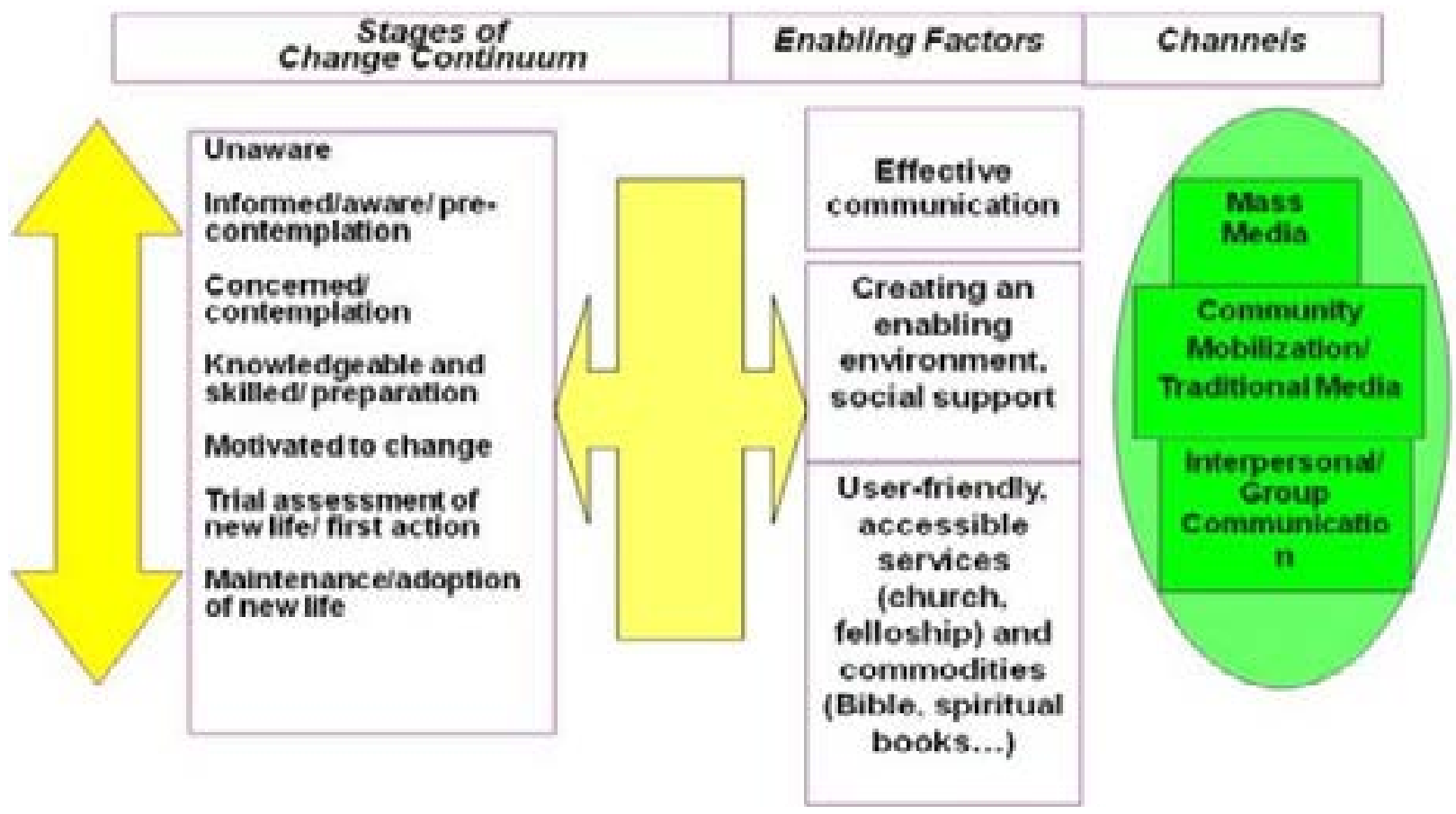

Figure 1: BCC Framework (Source: USAID, 2002:7)

\section{Stages of behavior change}

i) Pre-contemplative/unaware

At this stage, there is no commitment on the part of the individual to change his or her behavior in the foreseeable future.

\section{ii) Contemplative/aware}

The second stage is where people are aware that a problem exists and are earnestly considering taking some action to address the problem.

iii) Preparations/concerned

This third stage involves both intent to change some behavior, usually minor, and often meeting with limited success.

\section{iv) Action/knowledgeable}

Action is the fourth stage where individuals genuinely adjust their behavior, experiences, or environment in order to overcome their problems or to meet their goals. While the chances of setback and temptation are very strong, there is also openness to receiving help and support. This stage is the 'willpower' stage and short-term rewards to sustain motivation are frequently used. v) Maintenance/motivated to change

The fifth stage, maintenance, is where people work to avert setback and merge the gains attained in the action stage. The maintenance of behavior change and the avoidance of setbacks are features of the maintenance stage. The previous behavior is now no longer seen as desirable and a number of coping strategies have been put in place and are working.

vi) Termination/advocacy/transcendence/practicing trial behavior change

The individual has no temptation of setback and has self-confidence in maintaining the change. At this stage advocacy plays a significant part in helping move other people along the behavior change path and needs to be encouraged and supported.

\section{Enabling factors}

Enabling factors describe the conditions needed to enable and motivate the target population to protect themselves from HIV infection ${ }^{11-13,19}$. These factors include: -Availability of basic information in easily understood and psychologically accessible formats.

-Community participation in defining and negotiating what they need to be protected from HIV. 
-Access to essential services and commodities to prevent or lower HIV risk.

-Supportive social norms for reinforcement of prevention behaviors.

-National and institutional policies that make it easy for citizens to practice, or be supported in their practice of HIV prevention behaviors.

National laws and policy governing institutional behaviors are enabling tools for HIV prevention. There is need for continual community mobilization for awareness and enforcement ${ }^{11-13,19}$.

\section{Channels}

A channel is a technique by which a message is disseminated. It is essential to know which channels can effectively reach a particular target population. Establishing the range of available channels is part of BCC assessment $^{6}$.

\section{The BCC framework in the context of Swaziland}

The advantages of using the BCC in the fight against HIV and AIDS includes the fact that it leads to increased knowledge about the pandemic, promotes essential attitude change, stimulates community dialogue, helps to reduce stigma and discrimination, can be used as a tool for advocacy, creates demand for information and promotes services for prevention, care and support as well as improve skills and sense of self efficacy ${ }^{6}$.

In Swaziland like in many parts of the world, HIV is primarily a sexually transmitted disease $e^{2-7,11-13,19,20}$. Advancement of a caring environment requires national and community-wide dialogue of relationships, sex and sexuality, risk behaviors, risk settings, and cultural practices that may escalate the likelihood of HIV transmission ${ }^{2,6}$. A supportive environment addresses issues of fear, stigma and discrimination, as well as effective policies and laws at both community and national levels $\mathrm{s}^{2,8-10,15,18,21}$. Thus effective BCC is crucial in setting the tone ${ }^{6}$. Through the country's efforts to reduce stigma and discrimination in a national HIV response, the country conducted a stigma index in 2011 to determine and document the experiences of stigma surrounding People Living with HIV (PLHIV). The index guided the development of the National Strategy for Combating HIV and AIDS Related Stigma and Discrimination Interventions ${ }^{4,5}$. Youth in Swaziland have advanced in assuming some HIV prevention strategies, which are not enough as behavior changes are not sustained over a long period ${ }^{5}$.
Still in the context of a supportive environment, the Swaziland Youth Policy in alignment with the National Multi-sectorial HIV/AIDS Policy seeks to create awareness on the consequences of HIV/AIDS and also ensures counselling, rehabilitation and care for HIV infected youth. The policy also strives to mitigate the forces that drive the rapid increase in HIV infection8,9.

In the context of HIV/AIDS prevention and control, the BCC model entails the use of communication approaches and tools to foster positive change in behavior as well as improve knowledge and attitudes about HIV and other sexually transmitted infections. However, the BCC models recognizes that presentation of facts alone does not guarantee behavior change and that change may take some time to occur. Behavior change interventions are, therefore, intended to accommodate the stage of behavior assumption of an individual or group and to deveop the desirable abilities that allow and sustain change ${ }^{17,22}$. It is in this regard that Swaziland's HIV and AIDS national response strategy includes knowledge and awareness, but HIV and AIDS is still high especially among the youth ${ }^{19}$.

\section{Methods}

A qualitative study design was employed for this study because the researcher was seeking to better understand the factors contributing to the transmission of HIV and AIDS among the female youth attending the Mbabane Public Health Unit (MPHU) for various health services. A qualitative approach is more suited to data involving logical probing to enhance a better understanding of the phenomenon and gradually transform the social problematic circumstances ${ }^{17,24}$.

\section{Population, sample and data source}

From their data base, the MPHU provides different services to the public such as Anti-Natal Care, Prevention from Mother to Child Treatment, HIV Testing Centre and attends to an average of about 697 females within the targeted age bracket per month. The study sampled 210 female youth between 16-24 years old who attended Mbabane Public Health Unit (MPHU) from 1st October 2014 to $31^{\text {st }}$ October 2015 excluding weekends. A mixture of simple random and convenient sampling was used. Both structured and semi structured questions were included in the questionnaires that were administered with the help of two trained research assistants. The questionnaire was written in both the native siSwati and English languages to cater for possible varying levels of education of the 
respondents. The ages of the respondents were divided into younger (16 - 20 years) and the senior youth (21 24 years). The target population took into account the age of consent in Swaziland, which is 16 years $^{23}$. A pilot study was conducted whereby the researcher distributed 10 questionnaires to the target population. After this exercise, it was found out that some respondents could not clearly understand certain questions in English thus a siSwati version was developed and also piloted to 10 respondents. During questionnaire roll-out, participants were made to choose the preferred version. The siSwati version was also piloted to about 10 of the clients who met the inclusion criteria.

Permission for the study was granted by the management of the MPHU, Ministry of Health and the Swaziland Scientific and Ethical Research Committee. Participation was voluntary and the objectives of the study were clearly explained and a letter of invitation was issued to participants. The participants signed an informed consent form before being interviewed. They were allowed to withdraw at any time and anonymity was assured.

\section{Data analysis}

Qualitative data was analyzed into themes ${ }^{17,24}$ in line with the BCC model. The population was profiled in terms of age, education, income status, employment status, HIV knowledge and behavioral factors. Quantitative data was summarized descriptively. Data was entered in Microsoft Access and analyzed using Microsoft Excel.

\section{Results}

\section{Demographics, educational status and income}

There were 245 questionnaires distributed, 35 were incomplete, leaving 210 valid questionnaires for analysis. The demographics of the respondents, education, income level, and employment status are given in Table 1. Most respondents were single (64\%). Almost half (45\%) had a high school education and most were unemployed (57\%). The majority of the respondents $(73 \%)$ earned 0 to $\mathrm{E} 999$ per month. $(\mathrm{E}=$ Emalangeni and E $1.00=\mathrm{ZAR}$ $1.00)$.

Table 1: Respondents' demographics, educational and income level, and employment status are given $(n=210)$

\begin{tabular}{lll}
\hline Factor & & Percentage \\
\hline Marital status & Single & 64 \\
& Married & 23 \\
Education & Co-habiting & 12 \\
& High School & 44 \\
& Secondary education & 26 \\
& Tertiary education & 20 \\
& Primary education & 7 \\
& None & 2 \\
Employment & Other & 1 \\
& Unemployed & 57 \\
& Employed & 32 \\
Income (E) & Self-employed & 10 \\
& No response & 1 \\
& $0-999$ & 73 \\
& $1000-1999$ & 13 \\
& $2000-2999$ & 7 \\
& $3000-3999$ & 3 \\
& $4000-4999$ & 1 \\
& 5000 and above & 1 \\
& No response & 1 \\
& Other & 1 \\
\hline
\end{tabular}


Sources of HIV Information and sexual practices and other behaviours

Respondents' main sources of HIV/AIDS information, sexual and other practices is given in Table 2. Most indicated $(52 \%)$ that health facilities were their main source of HIV and AIDS information. The majority of the re- spondents $(88 \%)$ reported to have one sexual partner. The pattern of condom usage indicated that $62 \%$ of the respondents sometimes use condoms with $38 \%$ using a condom during their last sexual encounter. A couple of risky behaviours were also mentioned which turned around could act as prevention strategies.

Table 2: Respondents' main sources of HIV/AIDS information and sexual practice $(n=210)$

\begin{tabular}{|c|c|c|}
\hline Factor & & Percentage \\
\hline \multirow[t]{4}{*}{ Source of HIV information } & Health facility & 52 \\
\hline & Radio & 33 \\
\hline & Television & 11 \\
\hline & Newspaper & 3 \\
\hline \multirow[t]{3}{*}{ Number of sexual partners } & One & 88 \\
\hline & More than one & 8 \\
\hline & No response & 4 \\
\hline \multirow[t]{4}{*}{ Condom use } & Sometimes & 52 \\
\hline & Always & 35 \\
\hline & Never & 11 \\
\hline & Not applicable & 1 \\
\hline \multirow[t]{4}{*}{ Condom use in last sexual encounter } & Yes & 60 \\
\hline & No & 38 \\
\hline & Not applicable & 1 \\
\hline & No response & 1 \\
\hline \multirow[t]{9}{*}{ HIVIAIDS prevention knowledge responses } & Using condoms & 66 \\
\hline & Assisting using gloves & 36 \\
\hline & Abstinence & 33 \\
\hline & Faithfulness & 10 \\
\hline & Avoidance of sharing & 7 \\
\hline & Adherence to medical & 6 \\
\hline & Knowledge of one's HIV status & 5 \\
\hline & Do not share toiletries & 2 \\
\hline & Do not abuse drugs & 0.5 \\
\hline \multirow[t]{6}{*}{ Risk behavior* } & Unprotected sex & 55 \\
\hline & Syringes/needles & 10 \\
\hline & Sharing toothbrushes & 2 \\
\hline & Unfaithfulness & 1 \\
\hline & Multiple partners & 1 \\
\hline & Ignorance & 1 \\
\hline
\end{tabular}

*Respondents were asked to indicate other risk behaviors and the values given indicate the number who cited that behavior 
Those who responded to the question why they did not use condom gave the reasons as given in Table 3. It is worth noting that the majority of the respondents did not respond to the why part of the question. The respondents gave the impression that they were informed about prevention of HIV infection as all of the parameters mentioned were preventative measures.

Table 3: Reasons for not using condoms

\begin{tabular}{ll}
\hline Response & Number of respondents \\
\hline My partner does not want it & 12 \\
I don't like it & 10 \\
I trust my partner & 7 \\
I am afraid to negotiate & 5 \\
I am married & 4 \\
My partner stays away & 3 \\
We forgot to use it & 3 \\
Allergic to latex & 2 \\
I am on pills & 1 \\
I love my husband & 1 \\
Total & 36 \\
\hline
\end{tabular}

The grouped responses to the open ended question on risk behavior indicated that fifty five (55) cited unprotected sex, ten (10) flagged the use of syringes/needles, two (2) stated sharing tooth brushes and one (1) each for unfaithfulness, multiple partners and ignorance. Most respondents indicated that they did not use alcohol $(n=195)$ or intravenous drugs $(n=203)$

On age of sex debut, 57 per cent started having sex between ages 16 - 19 years and 35 per cent between 20 - 24 years. Most are sexually active yet majority are not married. The results also indicated that 195 respondents out of 210 did not take alcohol, 203 out of 210 did not take drugs through injections (intravenous drugs).

\section{Discussion}

The majority of the respondents $(97 \%)$ indicated to be knowledgeable about HIV and AIDS, but risky sexual behavior still remained the major contributing factor to possible HIV infection. Casual sex, coupled with inconsistent condom usage and early sexual debut were prevalent among the respondents indicating resistance to behavior change. With $12 \%$ of respondents co-habiting, there is a likelihood that they may have multiple partners or change sexual partners since they are not legally bound or in a committed relationship.

Literature ${ }^{7,20,21,24-26}$ reveals that higher education is linked with better perception of HIV risk. More educated women are also likely to engage in safer sex than those who have only completed their primary education ${ }^{7,11-13,19}$. It is also known that educational level correlates with employment opportunities ${ }^{7,25}$. The respondents' level of education was another cause of concern as less than half (45\%) had attained a high school education and very few had a tertiary education. In this study more than half (57\%) of the respondents were unemployed. Unemployment is linked with income disparity, which is high in Swaziland and driving HIV infection ${ }^{10,15,24}$. Transactional sex or sex for favors is associated with income inequality, resulting in more young girls engaging in unsafe sex and in the process taking more risks towards HIV infection ${ }^{16}$. A 20 year old girl dated a married man of about 45 years and responding to one of the questions, she said "I dated him because I needed a modern cell phone like the rest of my friends"

Health facility emerged as the predominant source of HIV/AIDS information (57\%). Having health facility as the main source of HIV and AIDS information is good as it can be anticipated that the respondents stand a better chance to get clear and concise information from qualified personnel and this can also allow them the opportunity to access any HIV prevention services if needed. This environment can also ensure the establishment of youth-friendly sexual and reproductive health services in all public health centers in the country, where youth would feel at ease to discuss health issues concerning sexuality and the promotion of life skills under the guidance of health care professionals. 
Multiple concurrent sexual partners is documented as one of the principal drivers of HIV and AIDS ${ }^{2-7}$. The question regarding the respondents' number of sexual partners tested their pre-contemplative and unawareness of HIV and AIDS. The number of sexual partners the respondents mentioned was indicative of some level of behavior change and in line with their level of awareness since the majority $88 \%$ had one partner. However, the $9 \%$ who had more than one partner was a cause for concern given the cob-we spread nature of HIV.

Condom use results $(60 \%)$ gave an indication of some level of behavior change, which was slightly above average among the population ${ }^{11-13,19}$. However, those who indicated no condom use was indicative of resistance to behavior change, given the fact that most were not legally married. On risky behaviors, the majority of respondents mentioned unprotected sex. "When I asked my boyfriend that we should use a condom", he replies that "we do not eat sweets while wrapped in a packet" an 18 year old high school youth reported. Other risky behaviours reported included contact with blood of an infected person, not using gloves when helping a sick person, sharing needles and blood transfusion. Although the list was not exhaustive, only the unprotected sex parameter was a behavioral factor. The responses showed that the respondents did not know or differentiate between behavioral factors and risk factors, which could hinder behavior change.

Lack of alcohol and drug use indicated that the respondents had the potential to change their sexual behavior because they did not engage in practices, which promoted inappropriate behavior ${ }^{7}$. According to the Central Statistical Office of Swaziland ${ }^{23}$, engaging in sexual intercourse while under the influence of alcohol and drugs can compromise power relations, prejudice judgment and increase the possibility of engaging in risky sexual behavior thus delaying positive behavior change. "Alcohol can make you do silly things and I will never taste it", a 24 years old girl said. The fact that the respondents could not differentiate between risk factors and behavior calls for the delivery of accurate HIV and AIDS messages by health workers, counsellors, peer educators or other trained personnel. The difference between risk behaviors and risk factors in relation to HIV and AIDS should be emphasized. However, the results were encouraging and indicative that the respondents' levels of awareness of the preventative measures was high and were most likely to apply the appropriate protective methods to prevent HIV infection if only they changed their behavior.

There is a need for the development of policies and programs that will protect and capacitate young people, promote behavior change and contribute to the mitigation of the effect of HIV and AIDS. Youth involvement should be ensured in designing the interventions in order to guarantee relevance of programs to them and to ensure that they address the issues of behavior change $e^{7,8-10,14}$.

\section{Conclusions and recommendations}

The awareness of HIV/AIDS among the young women respondents was widespread. However, alongside the correct knowledge there still existed characteristics of being resistant to behavior change, because there was evidence of underestimation of HIV risk through engagement in behaviors that contributed to high HIV infections. Therefore, strategies and programs in the form of comprehensive HIV/AIDS education and information sharing must be put in place to enhance behavior change among the youth. A more supporting environment for the youth is needed in terms of employment, effective policies and laws. Health centers in Mbabane and the whole of Swaziland could be conducive environments and should promote youth reproductive health services since they were the popular source of HIV information.

\section{Conflict of interest}

None declared.

\section{References}

1. Birkmann J. Measuring vulnerability to promote disaster resilient societies: conceptual frameworks and definitions. In: Birkmann J, editor. Measuring vulnerability to natural hazards: Towards disaster resilient societies. New York: United Nations University Press; 2006.

2. Swaziland Ministry of Health. 12th round of national serosurveillance in women attending antenatal care services at health facilities in Swaziland. Mbabane: Swaziland Ministry of Health; 2010.

3. Tanzania Commission for AIDS (TACAIDS). National behaviour change communication guidelines on HIV and AIDS interventions. Dar es Salaam: TACAIDS; 2012.

4. UNAIDS and WHO. Joint United Nations programme on HIV/AIDS and World Health Organization. AIDS 
epidemic update; 2007; [cited 2014 Oct 27]. Available from: http://data.unaids.org/pub/epislides/2007/2007_ epiupdate_en.pdf

5. UNAIDS (Joint United Nations Programme on HIV/ AIDS). Tackling HIV/AIDS through social and behavior change communication; 2012. [cited 2015 Sep 8]. Available from: http://www.fhi360.org/sites/default/files/ media/documents/FHI $\% 20360 \% 20$ SBCC $\% 20$ and $\% 20$ HIV $\% 20$ Fact $\% 20$ Sheet $\% 20$.pdf

6. UNAIDS. Global report. UNAIDS report on the global AIDS epidemic 2013. Joint United Nations Programme on HIV/AIDS (UNAIDS); 2013.

7. USAID. United States Agency for International Development. Behavior change communication (BCC) for HIV/AIDS-A strategic framework; 2002. [cited 2014 Sep 12]. Available from: http://www.hivpolicy.org/Library/ HPP000533.pdf

8. SWABCHA (Swaziland Business Collision against HIV and AIDS). SWABCHA fact sheet: general overview HIV/AIDS; 2012. [cited 2014 Aug 6]. Available from: http://www.swabcha.org.sz/factsheet/HIV-AIDS.pdf 9. Swaziland Government. The national multi-sectoral HIV and AIDS policy: A nation at war with HIV and AIDS. Mbabane: Swaziland; 2006.

10. Swaziland Government. National HIV prevention policy. Mbabane: Swaziland; 2010.

11. Ndegwa IN, Wanderi MP, Mwisukha A. Factors influencing behaviour change for the prevention of the spread of HIV/Aids among students in Githunguri division, Githunguri district, Kiambu county, Kenya. Int J Bus Sociol Sci. 2012; 3(16):313-324.

12. NERCHA (National Emergency Response Council on HIV and AIDS). The National multisectoral HIV and AIDS framework (eNSF) 2014 - 2018. Mbabane: Swaziland; 2012.

13. NERCHA / UNAIDS. (National Emergency Response Council on HIV and AIDS and Joint United Nations Programme on HIV/AIDS). Swaziland HIV prevention response and modes of transmission analysis. Mbabane: Swaziland; 2009.

14. amfAR. The foundation for AIDS Research; 2014. Trans populations and HIV: time to end the neglect. April: 1-8. [cited 2015 Dec 23]. Available from: http://www. apa.org/pi/aids/programs/hope/training/hiv-transgender.pdf

15. NERCHA / UNAIDS (National Emergency Re- sponse Council on HIV and AIDS and Joint United Nations Programme on HIV/AIDS). Swaziland global Aids response progress reporting; 2014. [cited 2014 Aug 28]. Available from: http://www.unaids.org/sites/default/ files/country/documents/SWZ_narrative_report_2014. pdf

16. PEPFAR. U.S. President's emergency plan for AIDS relief. 2013. Swaziland operational plan report FY 2013; 2013. [cited 2014 Jul 18]. Available from: http://www. pepfar.gov/documents/organization/222183.pdf

17. De Vos A.S, Strydom H, Fouche CB, Delport CSL. Research at grass roots for the social sciences and human service professions. $3^{\text {rd }}$ edition. Pretoria: Van Schaik Publishers; 2007.

18. Municipal Council of Mbabane. Summary of annual performance assessment report for Mbabane urban local government, Swaziland local government project. Mbabane, Swaziland; 2013.

19. NERCHA /UNAIDS (National Emergency Response Council on HIV and AIDS and Joint United Nations Programme on HIV/AIDS). Swaziland HIV estimates and projections report; 2010. [cited 2014 Aug 28]. Available from: http://www.equinetafrica.org/bibl/ docs/SWAZ\%20HIVProjections2010.pdf

20. Barnett T, Whiteside A. AIDS in the twenty-first century: Disease and globalization. $2^{\text {nd }}$ edition. New York: Palgrave Macmillian; 2006.

21. Panos Institute Southern Africa. Media brief on prevention of mother-to-child transmission (PMTCT) of HIV in Swaziland; 2012. [cited 2014 Aug 21]. Available from: http://www.panos.org.zm/wp-content/uploads/2013/02/Panos-PMTCT-Swaziland.pdf

22. Essien EJ, Ogungbade GO, Ward D, Ekong E, Ross MW, Meshack A, Holmes L Jr. Influence of educational status and other variables on human immunodeficiency virus risk perception among military personnel: a large cohort finding. Mil Med. 2007; 172(11):1177-1181.

23. Central Statistical Office. Swaziland, and Macro International Inc. Swaziland 2006-07 demographic and health survey. Mbabane: Central Statistical Office and Macro International Inc; 2008.

24. Hofstee E. Constructing a good dissertation. Sandton: Interpagrk Books (PTY) LTD; 2011.

25. Ebeniro CD. Knowledge and beliefs about HIV/ AIDS among male and female students of Nigerian universities: J Comp Res Anthropol Sociol. 2010; 1(1):121-131. 
26. Ganle JK, Tagoe-Darko E, Mensah CM. Youth, HIV/ AIDS risks and sexuality in contemporary Ghana: examining the gap between awareness and behaviour change. Int J Humanit Sociol Sci. 2012; 2(21):88-99.

27. UNAIDS. Joint United Nations Programme on HIV/AIDS. Global Report: UNIADS Report on Global

AIDS Epidemic. 2010. Available from: http://www.unaids.org/globalreport/documents/20101123_GlobalReport_full_en.pdf

28. American Psychological Association. 2010. HIV/AID and the Transgender Population. 2010. Availablefrom: http:/ /www.apa.org/pi/aids/programs/hope/training/ hiv-transgender.pdf

29. Bankole A., Singh S., Woog V and Wulf D. Risk and Protection: youth in sub-Saharan Africa. Washington: The Alan Guttmacher Institute; 2004.

30. Michielsen K., Bosmans M. and Marleen -Temmerman M. Reducing HIV/AIDS in young people in Sub-Sahara Africa: gaps in research and the role of theory. 2008. Available from: http://www.gap.ugent.be/africafocus/ pdf/08Michielsen_Fullpaper.pdf 